\title{
NMR-based metabolomics reveals effect of Ganoderma boninense infection on oil palm leaf at 30 days post-infection
}

\author{
Azizul Isha ${ }^{1 *}$, Nor Azah Yusof ${ }^{2 *}$, Rosiah Osman $^{2}$, Mui-Yun Wong ${ }^{3}$, Siti Nor Akmar Abdullah ${ }^{3}$ \\ ${ }^{1}$ Laboratory of Natural Products, Institute of Bioscience, Universiti Putra Malaysia, 43400 UPM Serdang, Selangor, \\ Malaysia \\ ${ }^{2}$ Functional Devices Laboratory, Institute of Advanced Technology, Universiti Putra Malaysia, 43400 UPM Serdang, \\ Selangor, Malaysia \\ ${ }^{3}$ Institute of Plantation Studies, Universiti Putra Malaysia, 43400 UPM Serdang, Selangor, Malaysia
}

\author{
*Corresponding author: azizul_isha@upm.edu.my, azahy@upm.edu.my
}

\section{Abstract}

Basal stem rot is the major disease in oil palm industry that caused by a fungal named Ganoderma boninense (G. boninense) species. Infected palms are symptomless at the early stage of this disease which imposes difficulties in detecting the disease. Therefore, this study was carried out to obtain the ${ }^{1} \mathrm{H}$ NMR metabolomic profiling of both non-infected and $G$. boninense infected oil palm leaf at 30 days post-infection (dpi). This combination has provided a rapid approach in investigating the changes in the compound variations of non-infected and $G$. boninense infected oil palm leaf. Non-infected and $G$. boninense infected oil palm leaf at $30 \mathrm{dpi}$ was extracted using aqueous methanol (methanol: water, 80: $20 \mathrm{v} / \mathrm{v}$ ). The crude extracts obtained were analyzed by ${ }^{1} \mathrm{H}$ NMR-based metabolomics approach. Analysis of metabolomics data from ${ }^{1} \mathrm{H}$ NMR was conducted by multivariate data analysis of principal component analysis (PCA). Significant differences were found between the two groups. Compared to the non-infected leaf, the $G$. boninense infected leaf had higher relative abundance of choline, asparagine, alanine, succinic acid, gallic acid, epicatechin, trimethylamine, $\mathrm{N}$-acetylglucosamine, $\mathrm{N}$-acetyltyrosine, 6 -sitosterol, 2,3-butanediol, lactic acid, caffeic acid, $p$ hydroxybenzoic acid, $\alpha$-tocopherol, $\boldsymbol{b}$-cryptoxanthin and kaempferol. The non-infected leaf showed higher level of sucrose, xylose, $\alpha$-glucose, $S$-sulfocysteine and indole-3-acetic acid. NMR-based metabolomics applied in this study reveals that $G$. boninense alters a manifold of primary and secondary compounds in oil palm leaf.

Keywords: Ganoderma boninense; leaf; metabolomic profiling; nuclear magnetic resonance; oil palm; principal component analysis. Abbreviations: dpi_days post-infection; G. boninense_Ganoderma boninense; RWB_rubber wood block; PCA_principal component analysis.

\section{Introduction}

Basal stem rot disease caused by white rot fungus Ganoderma boninense ( $G$. boninense) is a major disease problem in oil palm (Elaeis guineesis Jacq.). Ganoderma stem rot disease can causes reduction yield of infected palms and direct loss of stand resulting in death (Flood et al., 2002). The infected young palm normally dies within 1 or 2 years, whereas mature trees can survive up to three years (Corley and Tinker, 2003).

In former times, symptoms such as wilting and falling leaf through malnutrition or the existence of basidiomata of the pathogen on the tree was the only disease diagnosis technique (Lelong et al., 2010). Currently, several diagnostic techniques such as enzyme-linked immunosorbent assay, polyclonal antibodies and polymerase chain reaction test were used to detect $G$. boninense infected oil palm (Utomo and Niepold, 2000).

Further work needs to be carried out to study the compounds alteration of $G$. boninense infected at early stage. NMR spectrometry is one of the most utilized methods for differentiation of metabolic contents alteration in various scientific fields (Mediani et al., 2012). The NMR measurements are non-destructive, non-selective, which allow simultaneous detection of diverse groups of secondary compounds besides abundant primary compounds (Kim et al, 2010; Li et al., 2007). The combination of multivariate statistical technique such as principal component analysis is a technique to decrease the large size of data sets to a more manageable size (Lee et al., 2011). Therefore, a simple and reliable method procedure for determination of compound variations in $G$. boninense in oil palm leaf at early stage i.e. $30 \mathrm{dpi}$ using NMRmetablomics approach has been developed in this study. In our previous work, study on $14 \mathrm{dpi}$ of non-infected and $G$. boninense infected oil palm leaf has been determined using the same method (Isha et al., 2019). Up to now, there are no studies reporting on $30 \mathrm{dpi}$ of non-infected and $\mathrm{G}$. boninense infected oil palm leaf. This enables comparing the compounds variation between non-infected and $G$. boninense infected oil palm leaf at $30 \mathrm{dpi}$. Furthermore, the 
compounds determined in this work will allow a more complete understanding of the compound variations in basal stem rot disease and can be implemented for early detection of this disease in the future.

\section{Results and Discussion}

\section{${ }^{1} \mathrm{H}$ NMR spectra and compounds identification}

In this study, metabolomics analysis was employed to differentiate the compounds variation between non-infected and $G$. boninense infected oil palm leaf at $30 \mathrm{dpi}$. Compound fingerprinting of the oil palm leaf was obtained by comparing the determined compound peaks with our previous work in detection of non-infected and G. boninense infected oil palm leaf at $14 \mathrm{dpi}$ (Isha et. al., 2019). Compounds from this plant including amino acids, sugars, phytosterol, tocopherol and phenolics were successfully determined. Fig. S1 and Fig. S2 show the ${ }^{1} \mathrm{H}-\mathrm{NMR}$ spectra and 2D J-resolved of oil palm leaf aqueous methanolic extracts (methanol: water, 80: $20 \mathrm{v} / \mathrm{v}$ ), respectively.

Table 1 shows the determined compounds from oil palm leaf extract and their signal characteristics. A total of 22 compounds were determined, including primary and secondary compounds. Phytosterol such as $B$-sitosterol were detectable at $\delta 0.72(\mathrm{~d}, J=6.0 \mathrm{~Hz})$ and $\delta 1.00(\mathrm{~s})$, whereas alanine was detectable at $\delta 1.48(\mathrm{~d}, J=10.0 \mathrm{~Hz})$. Lactic acid, 2,3-butanediol, $\alpha$-tocopherol, $\quad$-cryptoxanthin and $N$ acetyltyrosine were observed in aliphatic region between $\delta$ 1.12 and 1.92. Other compounds such as $N$ acetylglucosamine, trimethylamine, succinic acid and epicatechin were detectable between $\delta 2.04$ and 2.88.

Xylose, sucrose and $\alpha$-glucose were assigned in accordance with the signals showed in the carbohydrate region of $\delta 3.0$ -5.5 . The existence of xylose was confirmed by the peaks at $\delta 3.40(\mathrm{t}, J=10.0 \mathrm{~Hz})$ and $4.56(\mathrm{~d}, J=7.5 \mathrm{~Hz})$ whereas peaks of sucrose was observable at $\delta 4.16(\mathrm{~d}, J=9.0 \mathrm{~Hz})$ and $\delta 5.40$ (d, $J=4.0 \mathrm{~Hz}$ ). A doublet peak observed at $\delta 5.16(\mathrm{~d}, J=5.0$ $\mathrm{Hz})$ suggested the presence of $\alpha$-glucose. The presence of amino acids namely $S$-sulfocysteine and asparagine were confirmed between $\delta 3.48$ and 3.92. Indole-3-acetic acid and choline were observable at $\delta 3.64$ (s) and $\delta 3.20$ (s), respectively.

A number of phenolics were observed in region of aromatic $(\delta 5.5-8.0)$. Characteristic peaks of phenolics as gallic acid was detectable at $\delta 7.02$ (s) whereas caffeic acid was observed at $\delta 6.52(\mathrm{~d}, J=15 \mathrm{~Hz}), \delta 6.88(\mathrm{~d}, J=10.0 \mathrm{~Hz})$ and $\delta$ $7.16(\mathrm{~d}, J=10 \mathrm{~Hz})$. Meanwhile, kaempferol was detectable at doublet peak at $\delta \quad 6.76(\mathrm{~d}, J=2.5 \mathrm{~Hz}$ ) whereas $p$ hydroxybenzoic acid was detectable at $\delta 8.00(\mathrm{~d}, J=5.0)$.

\section{Discrimination of non-infected and G. boninense infected oil palm leaf}

Multivariate data analysis was applied in this study to determine the variations in the compounds of non-infected and infected leaf samples. Hence, PCA was utilized to examine the grouping features of the samples and analyze the compounds that contributed to the variation. As illustrated in Fig. 1A, non-infected and infected leaf samples could be discriminated clearly. The cumulatively accounted of the first two principal components (PC1 and PC2) was calculated to be $88.2 \%$ of the total variation. The two groups are separated mainly along the PC1 direction, which carries $66.9 \%$ of the total variance in the NMR data.

The compounds in the non-infected and infected leaf samples at $30 \mathrm{dpi}$ that could be distinguished using PCA is illustrated in the loading plot for PC1 (Fig. 1B). Analysis of the scores and loading plots show that, the concentrations of choline, asparagine, alanine, succinic acid, gallic acid, epicatechin, trimethylamine, $\mathrm{N}$-acetylglucosamine, $\mathrm{N}$ acetyltyrosine, 6 -sitosterol, 2,3-butanediol, lactic acid, caffeic acid, $p$-hydroxybenzoic acid, $\alpha$-tocopherol, $\beta$ cryptoxanthin and kaempferol were more abundance in infected leaf samples. Sucrose, xylose, $\alpha$-glucose, $S$ sulfocysteine and indole-3-acetic acid were more prominent in non-infected leaf samples.

Plants defence by pathogens may show various biochemical defence responses such as cell wall deposition of lignin and suberin, enzyme synthesis and accumulation of specific compounds (Daayf et al., 2000). It has been proposed that amino acid such as asparagine was involved in plant stress responses related to pathogen infections (López-Gresa et al., 2012). Asparagine has been known as a general nitrogen transporter and function as transamination in plant (Lam et al., 1995; Sardan et al., 2014). Aspartate was converted into asparagine by a glutamine-dependent asparagine synthetase in plant asparagine biosynthesis (Eason et al., 1996; Olea et al., 2004). Previously, study on asparagine synthetase in tomato leaf infected by Pseudomonas syringae found that, ammonium ions released from protein degradation and amino acid deamination were reassimilated through cytosolic glutamine synthetase/asparagine synthetase into asparagine which was compartmentalized in the cytoplasm of mesophyll cells and the vascular tissue of infected leaf (Olea et al., 2004). High levels of alanine and choline accumulated in infected leaf samples were determined in this work. Alanine was involved with the activation of a programmed cell death response in suspension cultures of Vitis labrusca. Alanine level was increased to promote cell death of the infected tissue exploits to facilitate invasion (Chen et al., 2006). The elevated of choline levels in leaf was related to an increase in the synthesis of membrane components after interacted with pathogen (McNeil et al., 2001). Titarenko et al. (1997) claimed that infected leaf induces choline synthesis through the jasmonic acid signal transduction pathway.-he accumulation of $p$-hydroxybenzoic acids, gallic acid and caffeic acid, epicatechin and kaempferol in infected leaf could be associated to the shikimic acid pathway (Fig. S3), which involved in synthesis of plant phenolics (Boudet, 2007; Hoffmann et al., 2004; Whiting, 2001). Simple carbohydrate precursors resulted from glycolysis and the pentose phosphate pathway were converted the three aromatic amino acids i.e. phenylalanine, tyrosine, and tryptophan in the shikimic acid pathway. Phenylalanine ammonia lyase mediated the cinnamic acid formation from phenylalanine by the elimination of an ammonia molecule (Taiz et al., 2015). The activity of phenylalanine ammonia lyase was increased by the pathogen infection, which triggered the transcription of messenger RNA and stimulated the synthesis of phenolic compounds (Mandal et al., 2010). In the phenolic biosynthetic branch, $p$ coumaric acid was converted into caffeic acid and ferulic acid whereas the formation of hydrobenzoic acid can be produced by side-chain degradation of hydrocinnamic acids (Kahn and Durst, 2000; Sircar and Mitra, 2009). 
Table 1. Assignments of NMR signals for compounds determined in ${ }^{1} \mathrm{H}$ and $2 D$ NMR spectra of oil palm leaf extracts with corresponding multiplicity ( $\mathrm{s}$, singlet; $\mathrm{d}$, doublet; $\mathrm{t}$, triplet; $\mathrm{dd}$, doublet of doublets; $\mathrm{m}$, multiplet) and scalar coupling constant ( $\mathrm{J}$, $\mathrm{Hz}$ ) values. Compound fingerprinting of the oil palm leaf was achieved by comparing the determined compound peaks with our previous work (Isha et. al., 2019).

\begin{tabular}{|c|c|c|}
\hline Peak no & Compounds & $\delta^{1} \mathrm{H}$ (multiplicity) \\
\hline 1 & Sucrose & $4.16(d, J=9.0 \mathrm{~Hz}), 5.40(d, J=4.0 \mathrm{~Hz})$ \\
\hline 2 & Xylose & $3.40(\mathrm{t}, \mathrm{J}=10.0 \mathrm{~Hz}), 4.56(\mathrm{~d}, \mathrm{~J}=7.5 \mathrm{~Hz})$ \\
\hline 3 & $\alpha$-Glucose & $5.16(d, J=5.0 \mathrm{~Hz})$ \\
\hline 4 & Choline & $3.20(\mathrm{~s})$ \\
\hline 5 & Asparagine & $3.92(\mathrm{~m})$ \\
\hline 6 & Alanine & $1.48(\mathrm{~d}, \mathrm{~J}=10.0 \mathrm{~Hz})$ \\
\hline 7 & S-Sulfocysteine & $3.48(\mathrm{dd}, J=5.0 \mathrm{~Hz}, 5.0 \mathrm{~Hz})$ \\
\hline 8 & Succinic acid & $2.4(\mathrm{~s})$ \\
\hline 9 & Gallic acid & $7.02(\mathrm{~s})$ \\
\hline 10 & Epicatechin & $2.88(\mathrm{dd}, J=10.0 \mathrm{~Hz}, 5.0 \mathrm{~Hz})$ \\
\hline 11 & Indole-3-acetic acid & $3.64(\mathrm{~s})$ \\
\hline 12 & Trimethylamine & $2.89(\mathrm{~s})$ \\
\hline 13 & $\mathrm{~N}$-acetylglucosamine & $2.05(s)$ \\
\hline 14 & $\mathrm{~N}$-acetyltyrosine & $1.93(\mathrm{~s})$ \\
\hline 15 & B-Sitosterol & $0.72(\mathrm{~d}, J=6.0 \mathrm{~Hz}), 1.00(\mathrm{~s})$ \\
\hline 16 & 2,3-Butanediol & $1.20(\mathrm{~d}, J=10.0 \mathrm{~Hz})$ \\
\hline 17 & Lactic acid & $1.12(\mathrm{~d}, J=10.0 \mathrm{~Hz})$ \\
\hline 18 & Caffeic acid & $6.52(\mathrm{~d}, J=15 \mathrm{~Hz}), 6.88(\mathrm{~d}, J=10.0 \mathrm{~Hz}), 7.16(\mathrm{~d}, J=10 \mathrm{~Hz})$ \\
\hline 19 & $p$-Hydroxybenzoic acid & $8.00(d, J=5.0)$ \\
\hline 20 & $\alpha$-Tocopherol & $1.36(\mathrm{~s})$ \\
\hline 21 & 8-Cryptoxanthin & $1.15(\mathrm{~s}), 1.70(\mathrm{~s}), 1.76(\mathrm{~s})$ \\
\hline 22 & Kaempferol & $6.76(\mathrm{~d}, J=2.5 \mathrm{~Hz})$ \\
\hline
\end{tabular}
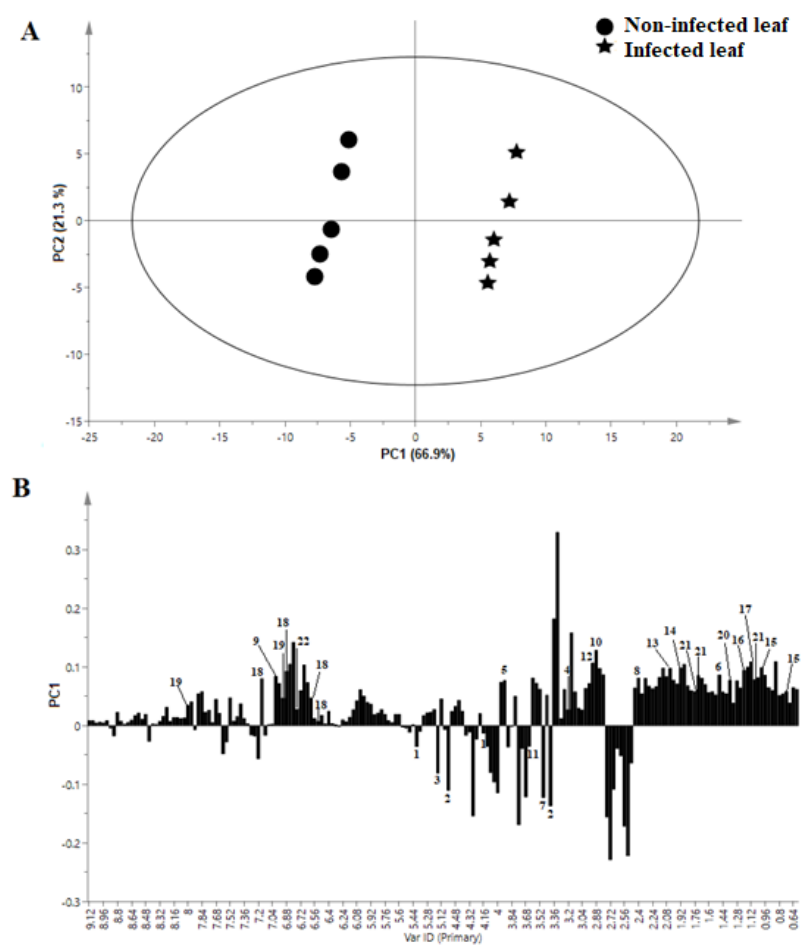

Fig 1. Principal component analysis (PCA) of ${ }^{1} \mathrm{H}$ NMR data of oil palm leaf aqueous methanolic extracts $A$. Score plot of PCA demonstrating differences in compound profiles of non-infected and $G$. boninense infected oil palm leaf at $30 \mathrm{dpi}$ B. loading column plot of PCA indicating primary differential compounds. Peak assignments: (1) sucrose, (2) xylose, (3) $\alpha$-glucose, (4) choline, (5) asparagine, (6) alanine, (7) S-sulfocysteine, (8) succinic acid, (9) gallic acid, (10) epicatechin, (11) indole-3-acetic acid, (12) trimethylamine, (13) $\mathrm{N}$-acetylglucosamine, (14) $\mathrm{N}$-acetyltyrosine, (15) B-sitosterol, (16) 2,3-butanediol, (17) lactic acid, (18) caffeic acid, (19) $p$-hydroxybenzoic acid, (20) $\alpha$-tocopherol, (21) b-cryptoxanthin, (22) kaempferol. 
$p$-Coumaric acid was converted into $p$-hydroxybenzaldehyde by the $p$-hydroxybenzaldehyde synthase enzyme without involve any co-factor. This aldehyde was then converted into $p$-hydrobenzoic acid by $p$-hydroxybenzaldehyde dehydrogenase activity. Benzoic acids act as precursors and signal molecules in which its methyl ester activated defencerelated genes in nearby plants and in healthy tissue of the infected plant (Abd El-Mawla and Beerhues, 2002; Shulaev et al., 1997).

In the flavonoid biosynthetic branch, trans-cinnamic acid was converted into 4-coumarate by cinnamic acid 4hydroxylase. It was catalyzed by 4-coumarate-CoA ligase to form 4-coumarate-CoA, followed by condensation of three units of malonyl-CoA by the first enzyme of the flavanoid pathway, i.e. chalcone synthase which produced naringenin chalcone (flavonone). Naringenin chalcone was converted into naringenin by the chalcone synthase and transformed into dihydrokaempferol after hydroxylated by flavonone-3hydroxylase. Dihydrokaempferol was then hydroxylated by flavanoid-3'-hydroxylase and converted into dihydroquercetin or hydroxylated by flavonoid-3'-5'hydroxylase to form dihydromyricetin. Flovonol such as kaempferol was synthesized by flavonol synthase at this stage. Leucocyanidin was obtained when dihydroflavonol reductase reduced dihydroquercetin. Leucocyanidin was reduced by leucocycyanidin reductase to obtain $(+)$ cetechin or reduced by anthocyanidin reductase to obtain (-) epicatechin (Gutierrez et al., 2017; Jiang et al., 2016). In the gallic acid biosynthesis, 3-dehydroshikimate was converted into 3,5-didehydroshikimate enzyme shikimate dehydrogenase. Then the latter compound spontaneously rearranged to gallic acid (Muir et al., 2011). The determined phenolic compounds in this study might be involved in the defense mechanisms of plants against fungal pathogen which also reported by other researchers (Cushnie and Lamb, 2005; Dixon and Paiva, 1995; Rodrigues et al., 2003). Beta-sitosterol is a plant sterol which play crucial roles in plant defense against pathogenic bacteria, fungi or insects (Harborne, 1991) and has been found accumulated in $G$. boninense infected leaf. Nusaibah et al. (2011) revealed that, B-sitosterol level was found higher in $G$. boninense infected oil palm seedling using GC-MS analysis. During the pathogen attack, the plant cell triggered plant defense response and initiates signaling events leading to enhanced expression of genes involved in sterol biosynthesis, leading to induction of stigmasterol (Wang et al., 2012). Catalization of squalene synthase was occurred in the first pathway-specific reaction of the sterol branch of the isoprenoid pathway in eukaryotes in which two molecules of farnesyl diphosphate were converted into the linear C30 terpenoid squalene (Fig. S4). Then squalene was epoxidase into 2,3-oxidosqualene through squalene epoxidase followed by formation of cycloartenol by cycloartenol synthase (Benveniste, 2004; Griebel \& Zeier, 2010). A dual biosynthetic pathway in higher plants leading to phytosterols has been reported by Ohyama et al. (2009) after they determined lanosterol synthase 1 in Arabidopsis. They found that the main part of the metabolic flux occurs through cycloartenol whereas a minor part occurs through lanosterol and LAS1. Various enzymatic steps such as reductases, methyl transferases, demethylases, isomerases and desaturases are needed to convert lanosterol or cycloartenol to b-sitosterol (Schaller,
2004). Beta-sitosterol was converted to stigmasterol by the cytochrome P450 CYP710A1 through C22 desaturation (Griebel and Zeier, 2010). The conversion of $B$-sitosterol to stigmasterol that is caused by pathogen infection could be suggested the higher level of $b$-sitosterol in infected leaf samples. Alpha-tocopherol or known as vitamin $E$ is synthesized by photosynthetic organisms (Boubakri et al., 2016). Several studies reported that the role of $\alpha$-tocopherol as cell signalling in plant (Munne-Bosch et al., 2007). Jasmonic acid and methyl-jasmonate which act as inducers of disease resistance in plants were reported to modulate the endogenous tocopherol level in the tocopherolbiosynthetic pathway (Antognoni et al. 2009; Gala et al. 2005) (Fig. S5). It enhanced transcription of homogentisate phytyltransferase genes and $p$-hydroxyphenyl pyruvate dioxygenase which increase the production of tocopherol. Lastly, $\alpha$-tocopheryl phosphate interacted with a receptor or transcription factor and modulated cell functions (Negis et al., 2006). This can be indicated that, the accumulation of $\alpha$ tocopherol in infected leaf is due to induce resistance of $G$. boninense infection. In contrast, sucrose, xylose and $\alpha$ glucose were decreased in oil palm leaf after infected with G. boninense at $30 \mathrm{dpi}$. This can be indicated that, a part of the existence carbon assembled in carbohydrates is possibly diverted towards secondary metabolism. It also provides the essential energy to assist increased secondary compounds biosynthesis (Hendrawati, 2006). In addition, the reduce of carbohydrates amount after infection by pathogen could be related with a mechanism for lifted of nutrients to other non-infected parts of plants (Rosta's et al., 2002). This is in agreement with other studies such as Chinese cabbage leaf infected Acholeplasma brassicae and Brasica rapa infected with pathogenic fungi which decreased the level of carbohydrates (Abdel-Farid et al., 2009; Rosta's et al., 2002).

Materials and methods

\section{Plant materials and sample preparation}

Plant materials used and preparation of samples were conducted according to our previous work reported in detection of $G$. boninense infected oil palm leaf at $14 \mathrm{dpi}$ (Isha et. al., 2019). Commercial DxP GH500 germinated seedlings of susceptible oil palm were purchased from Sime Darby Seeds \& Agricultural Services Sdn. Bhd., Banting. A total of ten germinated seedlings (five untreated seedlings (control); five treated seedlings with $G$. boninese inoculated rubber wood blocks (RWBs)) were used in this study. RWBs of size $6 \mathrm{~cm} \times 6 \mathrm{~cm}$ were applied as substrate for $G$. boninense and were prepared according to the methods described by Idris et al. (2006). Cultivation took place at the Transgenic Green House, Institute of Plantation Studies, UPM. Leaf samples were harvested at $30 \mathrm{dpi}$. Leaf samples were ground to the fine powder in liquid nitrogen, followed by freeze-drying using freeze dry system. Freeze-dried samples $(150 \mathrm{mg})$ were extracted in $250 \mathrm{~mL} 80 \%$ commercial-grade methanol (methanol: water, 80: $20 \mathrm{v} / \mathrm{v}$ ) $\left(30 \mathrm{~min}, 40^{\circ} \mathrm{C}\right.$ ) using sonicator. The residue was then reextracted twice following the same procedure. The supernatant was filtered and concentrated. The crude extracts obtained were stored at $-80^{\circ} \mathrm{C}$ for further analysis.

${ }^{1}$ H-NMR measurement and multivariate analysis 
The ${ }^{1} \mathrm{H}-\mathrm{NMR}$ and $J$-resolved analysis were analyzed using a $500 \mathrm{MHz}$ Varian INOVA NMR spectrometer (Varian Inc., Palo Alto, CA, USA), functioning at a frequency of $499.887 \mathrm{MHz}$ at room temperature $\left(25^{\circ} \mathrm{C}\right)$. The extraction procedures were performed according to our previous work (Isha et al., 2019). A $50 \mathrm{mg}$ sample was dissolved in $0.75 \mathrm{~mL}$ of deuterated solvent (1:1 mixture) consisting methanol- $d_{4}$ (99.8\%; Merck) and potassium dihydrogen phosphate buffer ( $\mathrm{pH}$ 6.0; Merck) in deuterium oxide (99.9\%; Merck) that contained $0.1 \%$ trimethylsilylpropionic acid- $d_{4}$ sodium salt (Merck). Then the mixture was vortexed $(1 \mathrm{~min})$ and ultrasonicated $(20 \mathrm{~min})$ at room temperature followed by centrifugation $(10,000 \mathrm{rpm}$, $10 \mathrm{~min})$ to obtain a clear supernatant. The supernatant (0.6 $\mathrm{mL}$ ) was transferred to an NMR tube to perform ${ }^{1} \mathrm{H}$ NMR analysis. The resulting spectra were manually phased and baseline corrected using the Chenomx software (v.5.1, Alberta, Canada). The data file was imported to SIMCA-P software (v. 13.0, Umetrics, Umeå, Sweden) for multivariate data analysis. PCA was performed with Pareto scaling method.

\section{Conclusion}

The results showed that ${ }^{1} \mathrm{H}$ NMR spectra of non-infected and $G$. boninense infected leaf at $30 \mathrm{dpi}$ exhibited differences which were discriminated and clustered into groups via PCA. A qualitative difference in plant compounds enhanced after infection. The increased levels of secondary compounds in plant-fungal interaction support their role in plant defence system.

\section{Acknowledgements}

This research was financially supported by the Ministry of Higher Education Malaysia, Long Term Research Grant Schemes (LRGS)-Nanomite and Universiti Putra Malaysia [grant numbers $5526304 \& 9443104$ ].

\section{References}

Abd El-Mawla AM, Beerhues L (2002) Benzoic acid biosynthesis in cell cultures of Hypericum androsaemum. Planta. 214: 727-733.

Abdel-Farid IB, Jahangir M, van den Hondel CAMJJ, Kim HK, Choi YH, Verpoorte R (2008) Fungal infection-induced compounds in Brassica rapa. Plant Sci. 176: 608-615.

Antognoni F, Faudale M, Poli F, Biondi S (2009) Methyl jasmonate differentially affects tocopherol content and tyrosine amino transferase activity in cultured cells of Amaranthus caudatus and Chenopodium quinoa. Plant Biol. 11(2): 161-169.

Benveniste $P$ (2004) Biosynthesis and accumulation of sterols. Annu Rev Plant Biol. 55:429-457.

Boubakri H, Gargouri M, Mliki A, Brini F, Chong J, Jbara M (2016) Vitamins for enhancing plant resistance. Planta. 244 (3): 529-543.

Boudet AM (2007) Evolution and current status of research in phenolic compounds. Phytochemistry. 68: 2722-2735.

Chen J, Hall DE, Murata J, De Luca V (2006) I-Alanine induces programmed cell death in $V$. labrusca cell suspension cultures. Plant Sci. 171: 734-744.

Corley RHV, Tinker PB (2003) Vegetative propagation and biotechnology. The Oil Palm, 4th edn, Wiley, Hoboken.
Cushnie TPT, Lamb AJ (2005) Antimicrobial activity of flavonoids. Int J Antimicrob Ag. 26: 343-356.

Daayf $F$, Ongena M, Boulanger R, El Hadrami I, Be' langer RR (2000) Induction of phenolic compounds in two cultivars of cucumber by treatment of healthy and powdery mildewinfected plants with extracts of Reynoutria sachalinensis. J Chem Ecol. 26: 1579-1593.

Dixon RA, Paiva NL (1995) Stress induced phenylpropanoid metabolism. Plant Cell. 7:1085-1097.

Eason JR, O'Donoghue EM, King GA (1996) Asparagine synthesisand localization of transcripts for asparagine synthetase in tips of harvested asparagus spears. J Plant Physiol.149: 251-256.

Flood J, Hasan Y, Turner PD, O'Grady EB (2000) The spread of Ganoderma from infective sources in the field and its implications for management of the disease in oil palm. In: Flood J, Bridge PD, Holderness M (eds) Ganoderma diseases of perennial crops. CABI Publishing, Wallingford, UK.

Gala R, Mita G, Caretto S (2005) Improving-tocopherol production in plant cell cultures. J Plant Physiol. 162(7): 782-784

Griebel T, Zeier J (2010) A role for B-sitosterol to stigmasterol conversion in plant-pathogen interactions. Plant J. 63: 254-268.

Gutierrez E, Velasco AG-V, Lucas JA, Gutierrez-Mañero FJ, Ramos-Solano B (2017) The flavonol-anthocyanin pathway in blackberry and arabidopsis: State of the art. In: Justino GC (ed) Flavonoids - from biosynthesis to human health. InTech

Harborne JB (1991) Role of secondary compounds in chemical defence mechanism in plants. In: Chadwick DJ, Marsh J (eds) Bioactive compounds from plants. John Wiley and Sons, Chichester.

Hendrawati O, Yao Q, Kim HK, Linthorst HJM, Erkelens C, Lefeber AWM, Choi YH, Verpoorte R (2006) Metabolic differentiation of Arabidopsis treated with methyl jasmonate using nuclear magnetic resonance spectroscopy. Plant Sci. 170: 1118- 1124.

Hoffmann L, Besseau S, Geoffroy P, Ritzenthaler C, Meyer D, Lapierre C, Pollet B, Legrand M (2004) Silencing of hidrocinnamoyl-Coenzym A shikimate/quinate hydroxycinnamoyl transferase affects phenylpropanoid biosynthesis. Plant Cell. 16: 1446-1465.

Idris AS, Kushairi A, Ariffin D, Basri MW (2006) Technique for inoculation of oil palm geminated seeds with Ganoderma. MPOB Info Series. 314: 1-4.

Isha A, Akanbi SF, Yusof NA, Osman R, Mui-Yun W, Abdullah SNA (2019) An NMR Metabolomics approach and detection of Ganoderma boninense-infected oil palm leaf using mwcnt-based electrochemical sensor, J Nanomater. 2019: 1-12.

Jiang N, Doseff Al, Grotewold E (2016) Flavones: From biosynthesis to health benefits. Plants. 5(2): 1-25.

Kahn RA, Durst F (2000) Function and evolution of plant cytochrome P450. Recent Adv Phytochem. 34: 151-189.

Kim HK, Choi YH, Verpoorte R (2010) NMR-based metabolomic analysis of plants. Nat Protoc. 5: 536-549.

Lam HM, Coschigano K, Schultz C, Melo-Oliveira R, Tjaden G, Oliveira I, Ngai N, Hsieh MH, Coruzzi G (1995) Use of 
Arabidopsis mutants and genes to study amide amino acid biosynthesis. Plant Cell. 7: 887-898.

Lee J, Lee B, Chung J, Shin H, Lee S, Lee C et al (2011) ${ }^{1} \mathrm{H}$ NMR-based metabolomics characterization during green tea (Camellia sinensis) fermentation. Food Res Int. 44: 597-604.

Lelong CC, Roger J-M, Brégand S, Dubertret F, Lanore $M$, Sitorus N, Raharjo D, Caliman J-P (2010) Evaluation of oilpalm fungal disease infestation with canopy hyperspectral reflectance data. Sensors. 10: 734-747.

Li L, Wang JN, Ren J, Xiang JF, Tang YL, Liu JX, Han D (2007) Metabonomics analysis of the urine of rats with $\mathrm{Qi}$ deficiency and blood stasis syndrome based on NMR techniques. Chinese Sci Bull. 52: 3068-3073.

López-Gresa MP, Lisón P, Kim HK, Choi YH, Verpoorte R, Rodrigo, Conejero V, Bellés JM (2012) Metabolic fingerprinting of tomato mosaic virus infected Solanum lycopersicum. J Plant Physiol. 169: 1586-1596.

Mandal SM, Chakraborty D, Dey S (2010) Phenolic acids act as signaling molecules in plant- microbe symbioses. Plant Signal Behav. 5(4): 359-368.

McNeil SD, Nuccio ML, Ziemak MJ, Hanson AD (2001) Enhanced synthesis of choline and glycine betaine in transgenic tobacco plants that overexpress phosphoethanolamine $N$ - methyltransferase. Proc Natl Acad Sci USA. 98: 10001-10005.

Mediani A, Abas F, Khatib A, Maulidiani H, Shaari K, Choi YH, Lajis NH (2012) ${ }^{1} \mathrm{H}-\mathrm{NMR}$ - based metabolomics approach to understanding the drying effects on the phytochemicals in Cosmos caudatus. Food Res Int. 49: 763-770.

Muir RM, Ibáñez AM, Uratsu SL, Ingham ES, Leslie CA, McGranahan GH, Batra N, Goyal S, Joseph J, Jemmis ED, Dandekar AM (2011) Mechanism of gallic acid biosynthesis in bacteria (Escherichia coli) and walnut (Juglans regia). Plant Mol Biol. 75: 555-565.

Munne-Bosch S, Weiler EW, Alegre L, Muller M, Duchting P, Falk J (2007) Alpha-tocopherol may influence cellular signaling by modulating jasmonic acid levels in plants. Planta. 225(3): 681-691.

Negis Y, Aytan N, Ozer N, Ogru E, Libinaki R, Gianello R, Azzi A, Zingg JM (2006) The effect of tocopheryl phosphates on atherosclerosis progression in rabbits fed with a high cholesterol diet. Arch Biochem Biophys. 450(1): 63-66.

Nusaibah SA, Siti Nor Akmar A, Mohamad Pauzi Z, Idris AS, Sariah M, (2011) Detection of phytosterols in Ganoderma boninense-infected oil palm seedling through GC-MS analysis. J Oil Palm Res. 23: 1069-1077.

Ohyama K, Suzuki M, Kikuchi J, Saito K, Muranaka, T (2009) Dual biosynthetic pathways to phytosterol via cycloartenol and lanosterol in Arabidopsis. Proc Natl Acad Sci USA. 106: 725-730.

Olea F, Pérez-García AR, Cantón FM, Rivera ME, Cañas $R$, Ávila C, Cazorla FM, Cánovas FM, de Vicente A (2004) Upregulation and localization of asparagine synthetase in tomato leaf infected by the bacterial pathogen Pseudomonas syringae. Plant Cell Physiol. 45(6): 770-780.

Rodrigues FA, Benhamou N, Datnoff LE, Jones JB, Bélanger RR (2003) Ultrastructural and cytochemical aspects of silicon-mediated rice blast resistance. Phytopathology. 93: 535-546.

Rosta's M, Bennett R, Hilker M (2002) Comparative physiological responses in Chinese cabbage induced by herbivory and fungal infection. J Chem Ecol. 28: 24492463.

Sardans J, Gargallo-Garriga A, Pérez-Trujillo M, Parella TJ, Seco R, Filella I, Peñuelas J (2014) Metabolic responses of Quercus ilex seedlings to wounding analyzed with nuclear magnetic resonance profiling. Plant Biol. 16(2): 395-403.

Schaller H (2004) New aspects of sterol biosynthesis in growth and development of higher plants. Plant Physiol Bioch. 42: 465-476.

Shulaev V, Silverman P, Raskin I (1997) Airborne signalling by methyl salicylate in plant pathogen resistance. Nature. 385: 718-721.

Sircar D, Mitra A (2009) Accumulation of $p$-hydroxybenzoic acid in hairy roots of Daucus carota 2: Confirming biosynthetic steps through feeding of inhibitors and precursors. J Plant Physiol. 166(13): 1370-1380.

Taiz L. Zeiger E, Møller IM, Murphy AS (2015) Plant physiology and development, 6th edn. Sinauer Associates, Sunderland CT.

Titarenko E, Rojo E, Leon J, Sanchez-Serrano JJ (1997) Jasmonic acid-dependent and -independent signaling pathways control wound-induced gene activation in Arabidopsis thaliana. Plant Physiol. 115: 817-826. Utomo C, Niepold F (2000) Development of diagnostic methods for detecting Ganoderma-infected oil palms. J Phytopathol. 148: 507-514.

Wang K, Senthil-Kumar M, Ryu CM, Kang L, Mysore KS (2012) Phytosterols play a key role in plant innate immunity against bacterial pathogens by regulating nutrient efflux into the apoplast. Plant Physiol. 158: 1789-1802.

Whiting DA (2001) Natural phenolic compounds 1900-2000: A bird's eye view of a centuries chemistry. Nat Prod Rep. 18: 583-606. 